\title{
Apoptotic Cell Death Induced by Optic Nerve Lesion in the Neonatal Rat
}

\author{
S. A. Rabacchi, L. Bonfanti, X.-H. Liu, and L. Maffei \\ Scuola Normale Superiore and Istituto di Neurofisiologia del CNR, 56127 Pisa, Italy
}

\begin{abstract}
Cell death can be ascribed to one of two distinct modes of degeneration: apoptosis (programmed or active cell death) or necrosis (passive degeneration). While apoptosis is generally assumed to occur in physiological conditions such as normal development or tissue turnover, necrotic cell degeneration is induced in pathological situations.

Here we report that also in a pathological situation, such as after axotomy in the CNS, apoptotic type of cell death comes into play: following intracranial transection of the optic nerve in the neonatal rat in vivo, retinal ganglion cells undergo an active, apoptotic cell death. In fact, the administration of protein synthesis inhibitors (actinomycin $D$ and cycloheximide) prevents the appearance of pyknotic nuclei as well as of fragmented DNA of ganglion cells at $24 \mathrm{hr}$ postlesion. Correspondingly, the number of surviving cells after actinomycin D and cycloheximide treatment is comparable to normal, unlesioned retinas. In addition, cycloheximide decreases the number of pyknotic ganglion cells during spontaneous cell death.
\end{abstract}

[Key words: axotomy, retinal ganglion cells, developing rat retina, DNA fragmentation, pyknosis, active cell death, protein synthesis inhibitors, neuronal degeneration, apoptosis, programmed cell death, retrograde degeneration]

Very little is known about the mechanisms of neuronal death following an injury to the nervous system. A lesion to the optic nerve has long been known to induce the death of most axotomized retinal ganglion cells both in the developing (Miller and Oberdorfer, 1981; Bcazley ct al., 1987; Harvcy and Robcrtson, 1992) and adult rat (Misantone et al., 1984; Villegaz-Perez et al., 1992), although the process is much more rapid in the young animal. The retrograde morphological alterations induced by the axotomy in the developing animal have been described, and include the appearance of pyknotic nuclei, characterized by a densely stained nucleus, and the presence of phagocytic cells often engulfing the degenerating cells (Miller and Oberdorfer, 1981; Beazley et al., 1987). However, the mechanisms leading to the degeneration of the axotomized neurons have not been elucidated.

\footnotetext{
Received Nov. 8, 1993; revised Jan. 4, 1994; accepted Jan. 24, 1994.

We are grateful to Dr. Burr, Dr. Jones, and Dr. Ratto for critical reading of the manuscript. Wc also thank Dr. Sassoon for advice regarding the $i$ in situ detection of fragmented DNA, Dr. Strettoi for help in morphological studies, Prof. Barsacchi for suggestions on amino acid incorporation experiments, and $\mathrm{Mr}$. Taccini and Mr. Margheritti for technical help. We are indebted to the International Institute for Paraplegia (Switzerland) for financial support.

Correspondence should be addressed to Sylvia Rabacchi, Istituto di Neurofisiologia del CNR, Via San Zeno 51, 56127 Pisa, Italy.

Copyright (C) 1994 Society for Neuroscience $0270-6474 / 94 / 145292-10 \$ 05.00 / 0$
}

It is often assumed that a pathological situation, such as trauma or ischemia, induces a necrotic type of cell death that involves the passive degeneration of cellular components including intracellular and cytoplasmic membranes (Wyllie et al., 1980; Duvall and Wyllie, 1986; Ellis et al., 1991; Raff, 1992). As a consequence of membrane disintegration, the dying cell releases cytotoxic compounds that contribute to generalized tissue inflammation. A very distinct mode of cell death is represented by apoptosis, an "active" process often requiring protein synthesis, common throughout the development of the nervous and immune systems, and also during normal tissue turnover (Ellis et al., 1991; Oppenheim, 1991; Cohen and Duke, 1992). This typc of cell death is also often referred to as spontaneous or programmed cell death. For its active properties, this type of cell death has also heen designated as "altruistic suicide" due to the considerable integrity of the dying cell membranes that spares neighboring cells from toxic products (Ellis et al., 1991; Raff, 1992). Apoptotic cells are, in fact, rapidly removed by phagocytic cells, thus preventing tissue inflammation. Besides often requiring protein synthesis, apoptosis is characterized by distinct morphological hallmarks: the integrity of cytoplasmic and intracellular membranes is accompanied by nuclear chromatin condensation (pyknosis) (Wyllie et al., 1980); in addition, a frequent biochemical feature is the cleavage of nuclear DNA at internucleosomal linker regions in fragments of multiples of the nucleosome (Cohen and Duke, 1992).

The presence of very different modes of cell death prompted us to analyze whether the degeneration of ganglion cells after section to the optic nerve could involve an active, apoptotic death. We chose to examine three criteria usually adopted to identify apoptosis: (1) dependence of cell death on RNA and protein synthesis, (2) appearance of pyknotic cells, (3) appearance of DNA fragmentation. Neonatal retinal ganglion cells were chosen as an experimental model due to the rapidity of the death process at younger age; given the toxicity of a long-term treatment with inhibitors of protein synthesis, only a system characterized by a short delay in the injury response allows investigation of the active properties of the process. Our results show that optic nerve lesion in the neonatal rat induces the appearance of both pyknosis and DNA fragmentation in the axotomized cells. Furthermore, intraocular administration of two different protein synthesis inhibitors (cycloheximide and actinomycin D) remarkably reduces the number of pyknotic cells and of cells with fragmented DNA and increases the number of surviving cells. Contrary to previous experiments, these results show that an injury to the CNS, such as axotomy, can trigger an active cell death program, rather than a passive, necrotic degeneration. A better understanding of the mechanisms involved in the in- 
jury-induced neuronal degeneration has obvious implications for regeneration in the CNS.

\section{Materials and Methods}

Optic nerve lesion. We performed unilateral intracranial optic nerve transection on Long-Evans rats at PO (day of birth). Rat pups were anesthetized by hypothermia, and optic nerve transection was performed by suctioning the overlying cerebral cortex through a syringe needle. The section was performed at approximately $3 \mathrm{~mm}$ from the eye. Rats were allowed to recover and then returned to their mothers until sacrifice $(5-48 \mathrm{hr}$ postlesion).

Intraocular administration of protein synthesis inhibitors. At various times after optic nerve lesion, protein synthesis inhibitors (actinomycin $\mathrm{D}$, cycloheximide; both from Sigma) or saline were injected intraocularly $(250 \mathrm{nl})$ with a pulled micropipette and the use of a microinjector. The dose of both drugs was $2.5 \mu \mathrm{g}$ except in dose-response studies, where $0.25 \mu \mathrm{g}$ and $1.25 \mu \mathrm{g}$ were also tested. The injection was performed under a dissecting microscope at the ora serrata, in order to reach the posterior chamber of the eye.

Histology. Under deep chloral hydrate anesthesia, eyes were taken and fixed in $4 \%$ paraformaldehyde for approximately $12 \mathrm{hr}$. Retinas were dissected from the eye, flattened on gelatinized slides, and fixed with $2.5 \%$ glutaraldehyde and then with formaline-ethanol solution (1: 9). The whole-mounted retinas were then stained with cresyl violet $(0.1 \%)$ and analyzed.

The number of pyknotic profiles and the number of living cells were counted by following a "blind procedure" in the ganglion cell layer of $20(90 \times 90 \mu \mathrm{m})$ fields, equally distributed across the whole-mounted retinas. An eyepiece graticule and a $100 \times$ oil immersion objective were used. We estimated the total number of cells per retina by multiplying the average number of cells per field times the ratio of the total arca of each retina to field area. The criteria adopted in the quantitative analysis are described in Perry et al. (1983). Briefly, pyknotic cells were identified by the presence of darkly and uniformly stained nuclei, sometimes fragmented. When two or more fragments were seen within a cell's distance from each other, they were counted as one pyknotic cell.

Retrograde labeling of retinal ganglion cells with HRP. Three neonatal rats (P0) were used in order to quantify the number of ganglion cells in whole-mounted retinas. Under hypothermia anesthesia, two injections (1.5 $\mu$ each) of 30\% HRP (in 2\% DMSO saline solution) in each superior colliculus were performed slowly; animals were allowed to recover and returned to their mothers. Twenty-four hours were allowed for retrograde transport. Animals were perfused with $1 \%$ paraformaldehyde, $1 \%$ glutaraldehyde, in $0.1 \mathrm{M}$ phosphate buffer; retinas were dissected out and reacted as free floating for IIRP, according to Perry and Linden (1982). The retinas were then attached to a gelatinized slide in formal alcohol for $12 \mathrm{hr}$, dehydrated, and mounted in Depex. The quantitative analysis was performed according to the same criteria adopted for counting pyknotic profiles in whole-mounted retinas stained with cresyl violet.

Incorporation of ${ }^{35} S$-methionine. Neonatal rat pups were utilized for testing in vivo the efficacy of the administration of protein synthesis inhibitors. To define the appropriate time period for amino acid incorporation, initial experiments were carried out on normal unlesioned retinas $(n=36)$, treated with the two protein synthesis inhibitors; 3,6 , 9 , and $15 \mathrm{hr}$ were allowed for incorporation before processing (not shown). The results here reported come from neonatal rat pups $(n=$ 34) subjected to optic nerve section and injection with protein synthesis inhibitors (actinomycin D or cycloheximide) at, respectively, 12 and 18 hr postlesion. An intraocular injection of $40-50 \mu \mathrm{Ci}$ of ${ }^{35} \mathrm{~S}$-methionine (DuPont New England Nuclear; $1220 \mathrm{Ci} / \mathrm{mmol}$ ) was performed $3 \mathrm{hr}$ before the sacrifice. At various postlesion intervals rats were deeply anesthetized and their retinas rapidly dissected out. The tissue was homogenized in Tris $10 \mathrm{mM}, \mathrm{pH} 6.5$, and centrifuged at $1500 \times \mathrm{g}$, and the supernatant blotted to Whatman GF/A disks. Proteins were then precipitated with TCA (trichloroacetic acid) according to Di Stefano et al. (1985), and radioactivity was determined by scintillation counting.

In situ labeling of fragmented DNA. After optic nerve transection, 14 rat pups were intraocularly injected with either protein synthesis inhibitors or with saline. Eyes were taken $24 \mathrm{hr}$ later, immersion-fixed in $4 \%$ paraformaldehyde, embedded in paraffin, cut at $6 \mu \mathrm{m}$, and then processed according to the technique described in Gavrieli et al. (1992). In initial experiments, segments of rat adult intestine were processed in the same way. Briefly, after a treatment with proteinase $\mathrm{K}(20 \mu \mathrm{g} / \mathrm{ml})$ to dissociate proteins from DNA, sections were incubated with terminal deoxynucleotidyl transferase $(0.3 \mathrm{U} / \mu \mathrm{l}$; Boehringer $)$ and biotinylated dUTP (40 $\mu \mathbf{M}$; Boehringer). The reaction product was visualized with fluorescein-avidin (Vector). Negative controls did not include the enzyme or the nucleotides; in positive controls, sections were incubated with DNase $(1 \mu \mathrm{g} / \mathrm{ml})$ prior to the terminal transferase. Labeled and unlabeled cells were counted by following a "blind procedure" by the use of a $40 \times$ oil immersion objective in the retinal ganglion cell layer of three sections per retina. Each section was sampled in six fields ( 240 $\mu \mathrm{m}$ long each) equally distributed. The values were expressed as labeled cells per 1000 neurons for each sampled field (Fig. $8 \mathrm{~A}$ ); then, the percentage was calculated where $100 \%$ is represented by the number of labeled cells in saline-treated lesioned retinas. The counts of total cells (labeled plus unlabeled) (Fig. $8 B$ ) are expressed as number of cells in $100 \mu \mathrm{m}$.

\section{Results}

We have analyzed a series of parameters generally adopted to identify the apoptotic type of cell death: morphological appearance of pyknotic nuclei (condensed chromatin), fragmentation of the DNA, and dependence of the degeneration process on active gene expression.

\section{Analysis of pyknotic cells}

Previous studies indicated that a lesion to the ganglion cell axons in the neonatal rat leads to the appearance, within 1-2 d, of pyknotic ganglion cells that are then rapidly removed by phagocytic cells (Miller and Oberdorfer, 1981; Perry et al., 1983; Harvey and Robertson, 1992). Pyknosis has been reported to be induced exclusively in axotomized retinal ganglion cells. We first confirmed the appearance of chromatin condensation (pyknosis) in the ganglion cell layer at $24 \mathrm{hr}$ postlesion by performing intracranial optic nerve transection and analyzing eye sections stained with cresyl violet. Subsequently, we carried out most of our experiments on whole-mounted retinas stained with cresyl violet since pyknotic cells of the retinal ganglion cell layer can be more easily quantified than on eye sections. Figure $1 A$ shows whole-mounted retinas stained with cresyl violet $24 \mathrm{hr}$ after optic nerve lesion; pyknotic cells are very numerous and readily identifiable. In some cases, cells resembling phagocytic cells were found associated with pyknotic cells (Fig. 1D); they are likely to be macrophages, already described to migrate into a lesion site, engulf, and phagocytose a dying cell (Perry et al., 1983). In unlesioned retinas (Fig. 1C) pyknotic cells are very rare (on the average they are 0.5 per field).

We determined the time course of pyknosis in the ganglion cell layer at various times after the transection of the optic nerve (Fig. 2A, triangles); an increase in pyknotic nuclei was first observed at $15 \mathrm{hr}$ postlesion, followed by a peak between 24 and $36 \mathrm{hr}$ after the lesion. After $48 \mathrm{hr}$, pyknosis is reduced to control levels of unlesioned retinas. Previous studies have shown that axotomy through a retinal lesion leads to complete death of ganglion cells after 48-72 hr (Perry et al., 1983).

\section{Protein synthesis inhibitors decrease pyknosis and increase survival of axotomized ganglion cells}

Pyknosis. We investigated the effects of protein synthesis inhibitors on the degeneration of retinal ganglion cells after optic nerve lesion. We used two types of inhibitors: actinomycin D (ActD), an irreversible inhibitor of transcription, and cycloheximide $(\mathrm{CHX})$, a reversible inhibitor of translation.

Actinomycin D $(2.5 \mu \mathrm{g})$ and cycloheximide $(2.5 \mu \mathrm{g})$ were injected intraocularly at, respectively, 12 and $18 \mathrm{hr}$ after the lesion, and the number of pyknotic cells was determined at $24 \mathrm{hr}$ postlesion. The results show that both inhibitors are remarkably ef- 

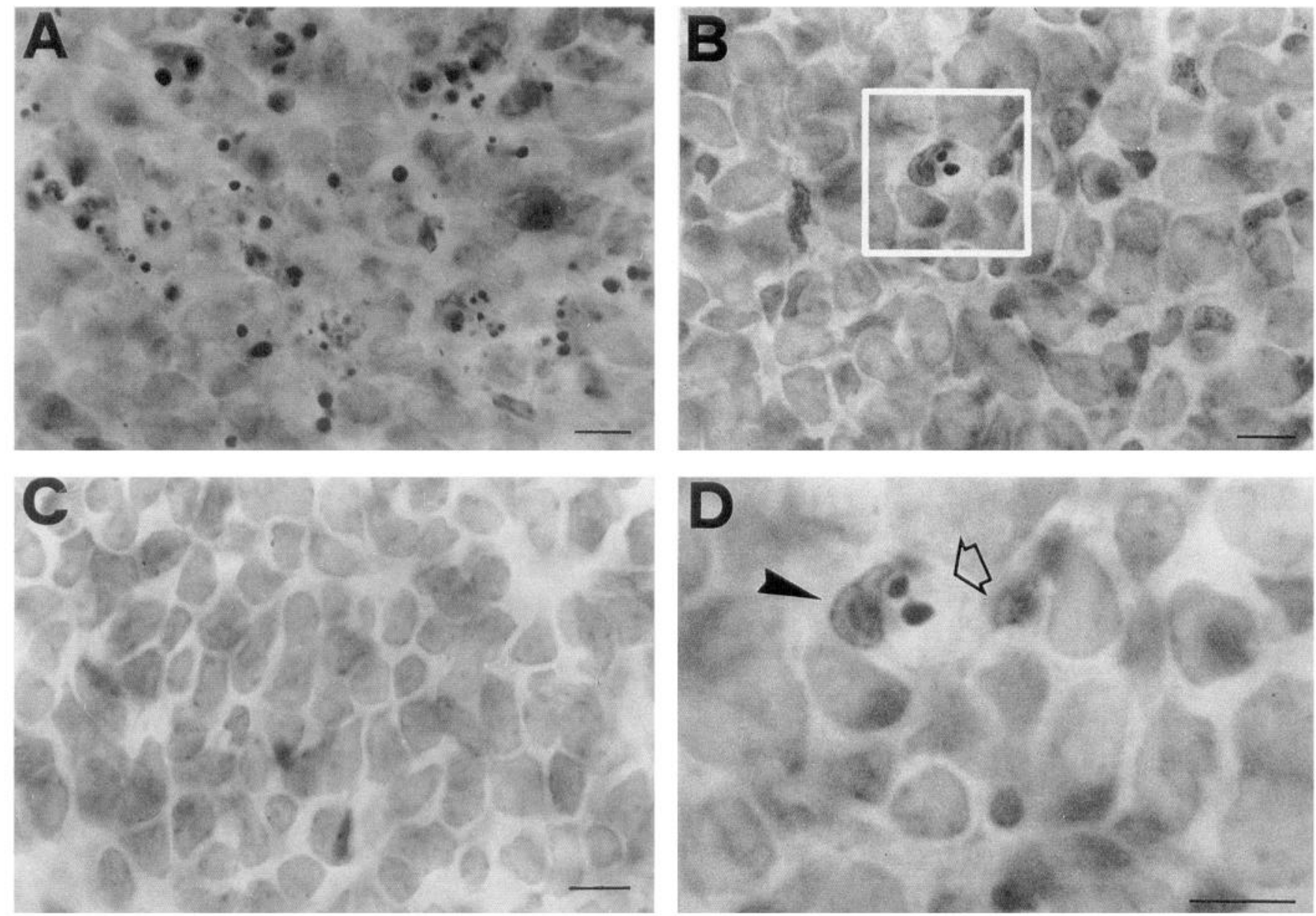

Figure 1. Cresyl violet staining of whole-mounted retinas at postnatal day 1 (P1) (focus on the ganglion cell layer). A, At $24 \mathrm{hr}$ after optic nerve section many pyknotic nuclei are present. $B$, Cycloheximide treatment reduces significantly the number of pyknotic cells present at 24 hr postlesion. $C$. Normal unlesioned retina. $D$, High magnification of a pyknotic cell (open arrow) engulfed by a phagocytic cell (solid arrowhead) marked by box in $B$. Scale bars, $10 \mu \mathrm{m}$.

fective in preventing retinal ganglion cell death. The number of pyknotic cells is dramatically reduced after this treatment (Figs. $2 A, 3)$. With actinomycin $\mathrm{D}$, the number of pyknotic cells 24 $\mathrm{hr}$ postlesion $(5310 \pm 2810, n=6)$ is decreased to $10 \%$ as compared to saline-injected lesioned retinas $(50,360 \pm 3060, n$ $=20$ ); in the case of cycloheximide, the number of pyknotic cells $(16,120 \pm 6890, n=14)$ is reduced to $32 \%$.

We next examined longer survival times by comparing eyes taken at 24, 36, and $48 \mathrm{hr}$ postlesion (Fig. $2 \mathrm{~A}$ ); after actinomycin $\mathrm{D}$ (solid circles), pyknosis is maintained at low levels even at $36-48 \mathrm{hr}$ postlesion, due to the irreversible properties of this drug. On the contrary, after cycloheximide, a dramatic increase in pyknotic cells occurs $36 \mathrm{hr}$ postlesion (open circles), consistent with the reversible property of cycloheximide. The overshooting observed at $36 \mathrm{hr}$ is probably caused by an accumulation of nontranslated mRNAs.

The efficacy of protein synthesis inhibition was verified by injecting ${ }^{35} \mathrm{~S}$-labeled methionine intraocularly in normal and lesioned eyes of rat pups treated with protein synthesis inhibitors and by quantifying amino acid incorporation into proteins. Initial experiments performed on unlesioned eyes revealed that a period of $3 \mathrm{hr}$ is sufficient to yield high amino acid incorporation (not shown). Therefore, we allowed a $3 \mathrm{hr}$-incorporation period and applied the above-described protocol of optic nerve lesion and intraocular injections. The results (Fig. $2 B$ ) show that, at $24 \mathrm{hr}$ postlesion, both treatments significantly prevent the incorporation of labeled methionine; actinomycin D decreases protein synthesis to $50 \%$, while cycloheximide to $13 \%$, when compared to saline-treated animals. At $36-48 \mathrm{hr}$ postlesion protein synthesis resumes, in the case of the reversible drug cycloheximide, while it is still inhibited after actinomycin D treatment (irreversible blocker). The comparison of Figure 2, $A$ and $B$, shows a striking parallel between the pattern of pyknosis and protein synthesis; indeed, it can be noted that in the case of cycloheximide, when protein synthesis resumes (Fig. $2 B$ ), at $36 \mathrm{hr}$, the level of pyknosis increases dramatically (Fig. $2 A$, open circles). In the case of actinomycin D, at 36-48 hr, protein synthesis is still inhibited and, correspondingly, pyknosis is maintained low. The effects of inhibition of protein synthesis on pyknosis and the temporal correspondence between protein synthesis and pyknosis point to a critical role of RNA and protein synthesis in the process of degeneration of axotomized retinal ganglion cells.

Survival. In order to count surviving ganglion cells, we assumed that all or most cells counted in the retinal ganglion cell layer are ganglion cells. Indeed, previous observations (Perry et al., 1983) have shown that, in the neonatal retina, amacrine cells represent less than $5-10 \%$ of the entire cell population of 


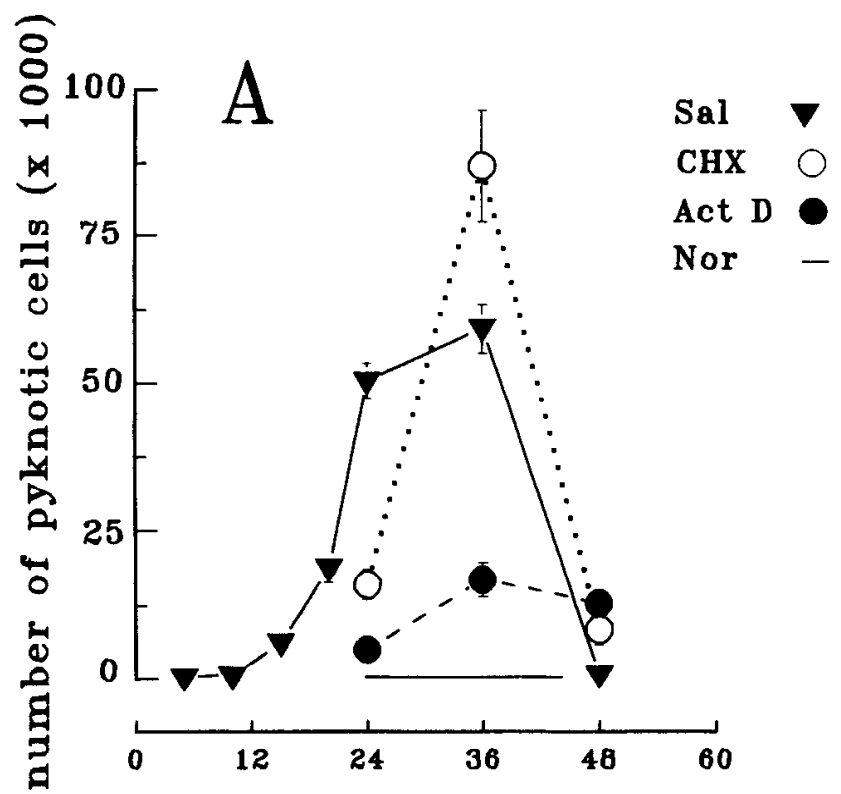

Hours post-lesion

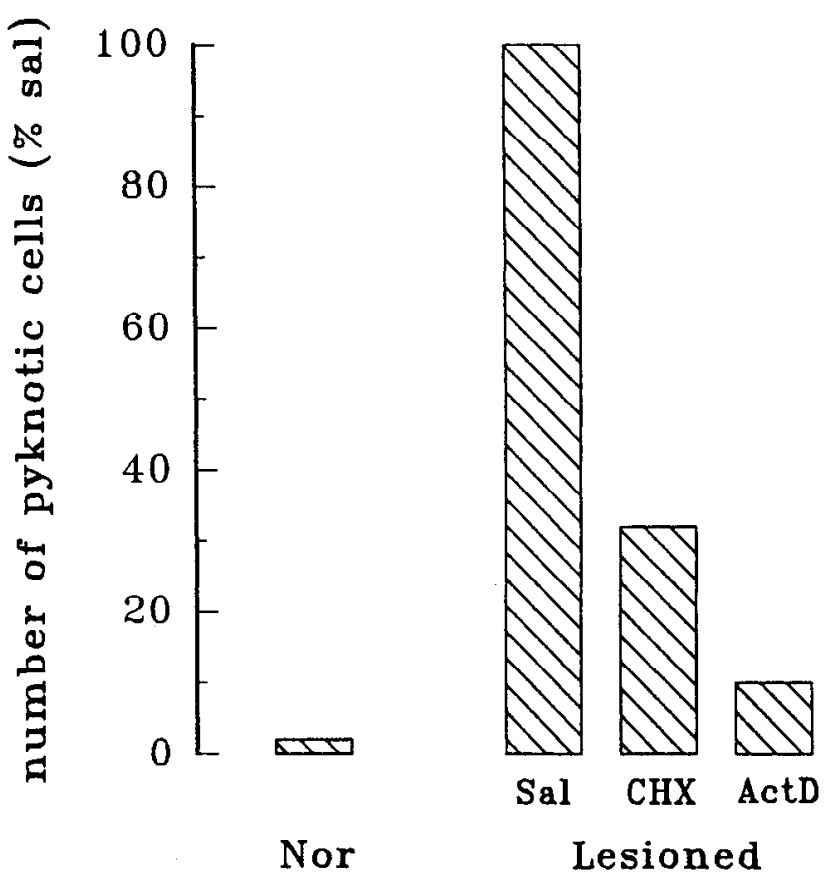

Figure 3. Effects of protein synthesis inhibitors on pyknosis, expressed as percentage of saline. Both inhibitors of protein synthesis prevent significantly $(p<0.001)$ the appearance of pyknotic ganglion cells at $24 \mathrm{hr}$ after optic nerve lesion, when compared to saline-injected lesioned retinas. With actinomycin D pyknosis decreases to $10 \%$, while cycloheximide reduces pyknosis to $32 \%$.

this layer. In order to confirm this result in our system, retinal ganglion cells were retrogradely labeled in three neonatal rats, by injecting HRP in both superior colliculi; the total number of labeled ganglion cells estimated to be present in the entire retina is 240,000 ( $\pm 15,947 \mathrm{SE})$ (data not shown). Since the total number of cells counted in the ganglion cell layer of cresyl violetstained whole mounts is on the average $250,000( \pm 16,332 \mathrm{SE})$ (see Fig. 4), we confirm that amacrine cells represent approximately $5 \%$ of the total cells of this layer at postnatal day 1 . Given the small contribution of this class of cells, we carried out most of our experiments based on cresyl violet counts. The small cells (diameter $<6 \mu \mathrm{m}$ ), described to be glial cells (Miller and Oberdorfer, 1981), were excluded from our analysis.

If the administration of protein synthesis inhibitors is really reducing cell death, one should expect to find a corresponding increase in surviving cells; alternatively, the decrease in pyknosis could be due to a faster clearance of dead cells. We have indeed found that at $24 \mathrm{hr}$ postlesion the inhibition of protein synthesis increases significantly the survival of axotomized retinal ganglion cells (Fig. 4). The number of living cells following an optic nerve section is much greater in animals that have been treated with either actinomycin $\mathrm{D}(p<0.05)$ or cycloheximide $(p<0.05$ ), when compared to control (saline). It should be

\section{Hours post-lesion}

Figure 2. Effects of protein synthesis inhibitors on the degeneration of axotomized retinal ganglion cells. $A$, Time course of pyknosis in the retinal ganglion cell layer. With control solution ( $\mathrm{Sal})$, the number of pyknotic cells starts to increase $15 \mathrm{hr}$ postlesion, reaching a peak between 24 and $36 \mathrm{hr}$ postlesion. Cycloheximide $(\mathrm{CHX})$ is effective in preventing pyknosis at $24 \mathrm{hr}$ postlesion and not at longer time intervals, due to its reversible properties. On the contrary, being its effect irreversible, actinomycin D (Act D) exerts long-lasting effects. At $24 \mathrm{hr}, n=20$ for saline, $n=16$ for cycloheximide, and $n=8$ for actinomycin D trcatments. For other time points $n=3-8$. Error bars indicate SE, and, where not seen, are within the symbol. $B$. Incorporation of ${ }^{35}$ S-methionine into proteins in $\mathrm{P} 1$ retinas expressed as percent of saline-injected lesioned retinas. Injection of cycloheximide (open circles) reduces protein synthesis to $13 \%$ at $24 \mathrm{hr}$ postlesion, but this rebounds later to $125 \%$, consistent with its reversible property. Actinomycin D (solid circles) decreases aminoacid incorporation to $50 \%$ at $24 \mathrm{hr}$, and this remains at approximately $13 \%$ thereafter, as this drug is not reversible. Each value represents a single retina. 


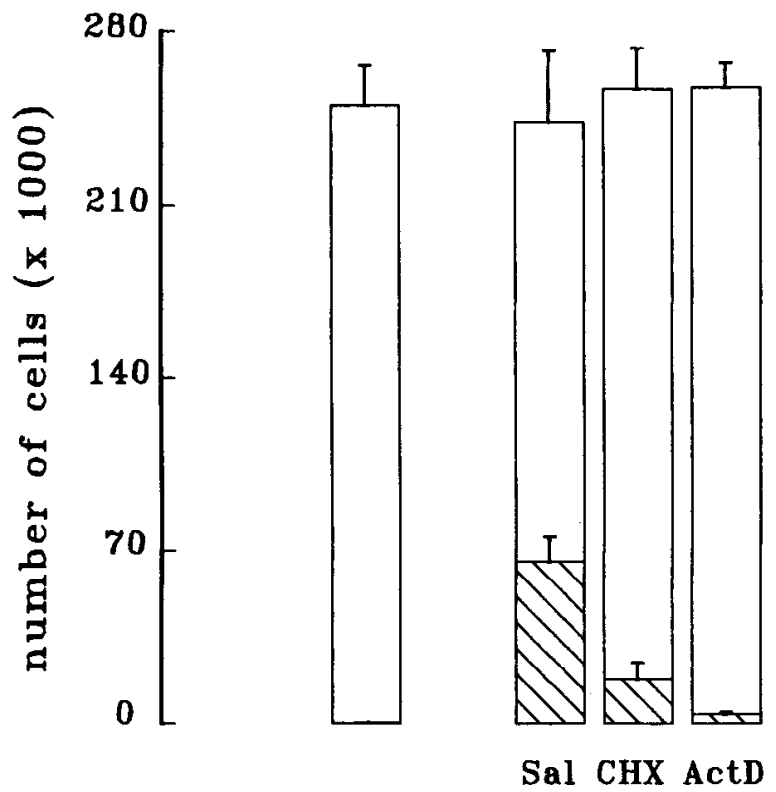

Nor

\section{Lesioned}

Figure 4. Effect of protein synthesis inhibitors on the survival of axotomized retinal ganglion cells, at $24 \mathrm{hr}$ postlesion. Open bars represent the total number of cells (pyknotic plus surviving), while solid bars represent the number of pyknotic cells. The number of surviving cells after treatment with both protein synthesis inhibitors is significantly different from saline $(p<0.05)$, but not different from normal unlesioned retinas (Nor). The total number of cells counted in lesioned and unlesioned retinas is comparable in all four bars $(p>0.05)(n=3$ for each column). Error bars indicate SE.

noted that after actinomycin $\mathrm{D}$ and cycloheximide administration, the number of surviving cells is comparable to that of normal, unlesioned retinas ( $p=0.42$ and $p=0.73$, respectively). Considering that a pyknotic ganglion cell is estimated to last 3$4 \mathrm{hr}$ (Horsburgh and Sefton, 1987; Harvey and Robertson, 1992), those cells appearing pyknotic at $20 \mathrm{hr}$ postlesion could still be found (and therefore counted) at $24 \mathrm{hr}$. The cell loss up to 24 $\mathrm{hr}$ is not, therefore, substantial and this might explain why the total number of pyknotic plus surviving cells at $24 \mathrm{hr}$ (Fig. 4, Sal) after the lesion is not statistically lower than normal (Nor).

Initial experiments included multiple injections of cycloheximide (injections $4 \mathrm{hr}$ apart); the efficacy of this protocol is even greater when compared to the single-injection protocol. Subsequently, we investigated the temporal window in which the blockade of transcription and translation is effective; this information could elucidate the time course of the molecular events leading to cell death. To achieve this, we performed a single injection at different postlesion intervals and analyzed the level of pyknosis in the retinas $24 \mathrm{hr}$ postlesion. Our results show that actinomycin D (inhibitor of transcription), injected later than $12 \mathrm{hr}$ postlesion, is ineffective in preventing ganglion cell death (see Fig. 5, ActD, 20h), suggesting that at this time the transcription of some "killer gene" has already been triggered. As for cycloheximide, a reversible blocker of translation, its administration should be performed not later than $20 \mathrm{hr}$ after the lesion, in order to prevent the appearance of pyknosis (not shown). The high number of pyknotic cells observed after an injection of cycloheximide at $12 \mathrm{hr}$ (see Fig. 5, CHX, 12h) is probably due to the reversible effect of this drug, that has been
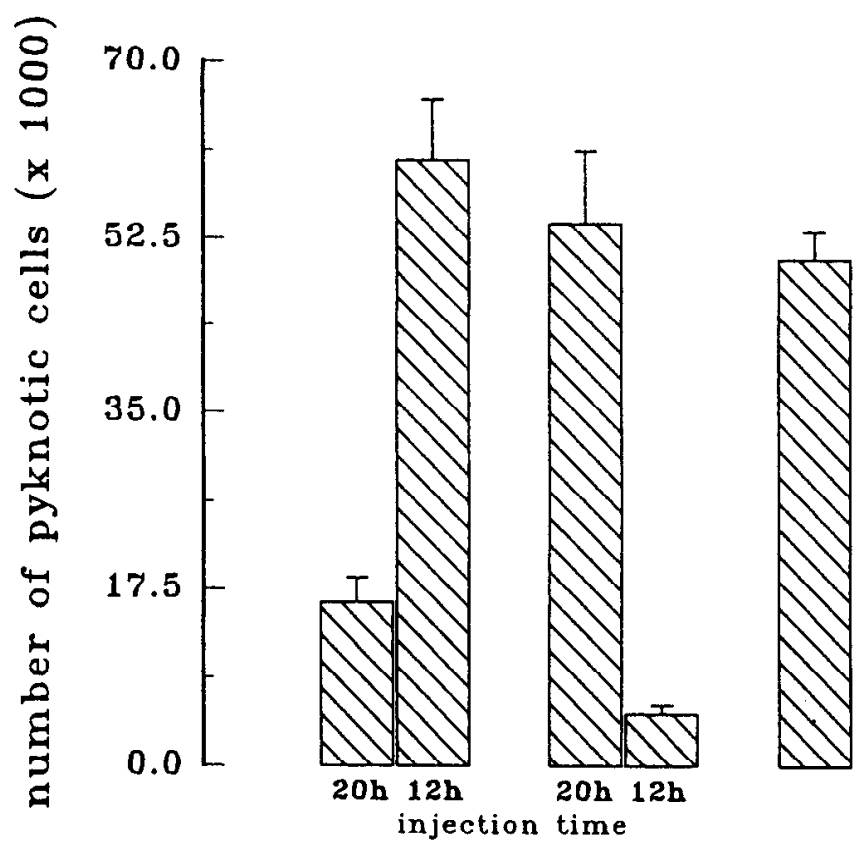

CHX ActD

Sal

Figure 5. Effects of protein synthesis inhibitors administered at different times after the lesion. The effective time for inhibition is, respectively, 12 and $20 \mathrm{hr}$ for actinomycin $\mathrm{D}$ and cycloheximide. The injection of actinomycin D as late as $20 \mathrm{hr}$ is completely ineffective in preventing pyknosis; similarly, cycloheximide administered as early as $12 \mathrm{hr}$ is also ineffective ( $n=3$ for each bar).

estimated to last only $3-4 \mathrm{hr}$. The comparison between transcription and translation inhibitors suggests that the transcription of some toxic gene(s) begins at around $12 \mathrm{hr}$ postlesion, while the synthesis of the corresponding protein(s) occurs after $20 \mathrm{hr}$ postlesion.

A series of experiments was performed to verify whether the effect of protein synthesis inhibition is dose depcndent. Doseresponse studies have revealed that $2.5 \mu \mathrm{g}$ of each inhibitor is sufficient to exert the protective effects presented here, while $1.25 \mu \mathrm{g}$ gives incomplete neuronal protection and $0.25 \mu \mathrm{g}$ no effect at all.

\section{Protein synthesis inhibition and natural cell death}

We have also tested the effects of intraocular administration of actinomycin D and cycloheximide on the spontaneous degeneration of retinal ganglion cells, known to occur mostly in early postnatal life (P0-P10) (Lam et al., 1982; Potts et al., 1982; Perry et al., 1983). Experiments performed on $11 \mathrm{P} 1$ rat pups ( 80 fields of $90 \times 90 \mu \mathrm{m}$ were sampled) have shown that a short treatment with cycloheximide can prevent the appearance of pyknotic cells in the ganglion cell layer. The number of pyknotic cells is reduced from $1500( \pm 333 \mathrm{SE})$ to $500( \pm 115 \mathrm{SE})$ after 4 $\mathrm{hr}$ from the intraocular injection ( $p<0.05$, data not shown). The analysis of the effects of protein synthesis inhibition on the natural cell death of ganglion cells has, however, some difficulties. Up to $60 \%$ of the entire ganglion cell population disappears due to natural cell death, but this process takes over $10 \mathrm{~d}$ to take place; therefore, due to the short duration of a pyknotic cell (estimated to be in the order of 3-4 hr), the number of pyknotic cells at any given time is extremely low (see Fig. 3, 

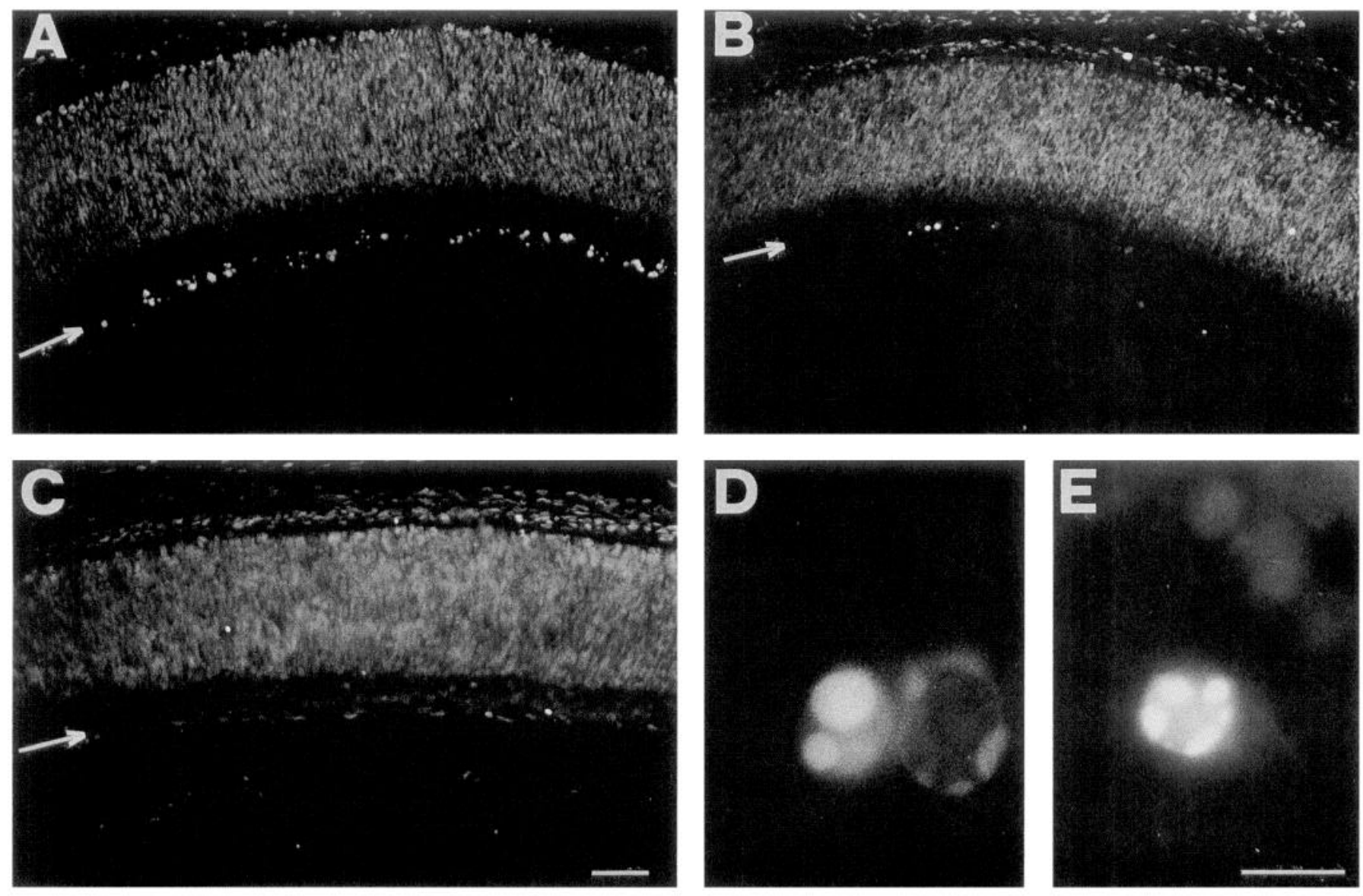

Figure 6. In situ labeling of DNA fragmentation in retinal sections $(6 \mu \mathrm{m})$ at P1, using terminal deoxynucleotidyl transferase and biotinylated dUTP. Ganglion cell layer is indicated by an arrow. $A$, Twenty-four hours after optic nerve transection; the arrow shows many labeled cells in the ganglion cell layer. $B$, Twenty-four hours postlesion, but treated with cycloheximide; very few cells are labeled in the ganglion cell layer. $C$, Normal unlesioned eye. $D$ and $E$, High magnification of labeled cells displaying characteristic features of fragmented nuclei (apoptotic bodies). Scale bars: $A-C, 50 \mu \mathrm{m} ; D$ and $E, 10 \mu \mathrm{m}$.

Nor). An additional difficulty is that repetitive injections of cycloheximide for more than $12 \mathrm{hr}$ lead invariably to the death of the animal because of loss of metabolic activity.

\section{Analysis of DNA fragmentation}

A common feature often associated with apoptosis is the degradation of nuclear DNA into nucleosome-sized oligomeres, giving rise to a typical "ladder" pattern when the DNA is run on an electrophoresis gel (Cohen and Duke, 1992). However, in our model, this technique might not be sensitive enough to detect DNA fragmentation in the lesioned retina, as only the ganglion cells, a small fraction of the total cell population of the retina, are affected by an optic nerve lesion. Therefore, we applied a recently described morphological technique of detecting fragmented DNA in situ (Gavrieli et al., 1992). This method allows the detection of nicked DNA in cells undergoing apoptosis, by the use of the enzyme terminal transferase; an incubation of a tissue section with this enzyme along with biotynilated nucleotides allows the visualization of cells presenting fragmented DNA.

We first applied this technique to rat intestinal tissue, where it had been previously shown to label only cells located at the tips of the villi, corresponding to the location of apoptotic cells (not shown; Gavrieli et al., 1992). After confirming this result, we analyzed the presence of DNA fragmentation in the retina
$24 \mathrm{hr}$ after a lesion to the optic nerve. Similarly to cresyl violet staining, this method shows that such a lesion induces the appearance of labeled nuclei in the retinal ganglion cell layer (Fig. $6 A$ ). Frequently, labeled cells closely resemble the aspect of typical apoptotic bodies revealed by cresyl violet (Figs. $1 D$, $6 D, E)$. Some rare labeled cells are seen (at low magnification), particularly in the ganglion cell layer of normal, unlesioned retinas; they most likely represent ganglion cells undergoing naturally occurring cell death, that is known to take place at this time of retinal development (Fig. 6C). The number of cells presenting DNA fragmentation is approximately of the same order as that of pyknotic cells. Figure 7 shows a section processed first for DNA fragmentation detection $(B)$ and then later stained with cresyl violet $(A)$; it can be noted that the two cells revealing DNA fragmentation are also pyknotic. In a quantitative study, performed at $24 \mathrm{hr}$ postlesion on adjacent eye sections, we found that the number of pyknotic cells is comparable to that of DNAfragmented cells. This correlation, however, does not exclude that the two processes (pyknosis and DNA fragmentation) diverge at other time windows after the lesion.

\section{Protein synthesis inhibitors decrease the number of cells displaying DNA fragmentation}

Blockade of RNA and protein synthesis largely prevents the fragmentation of DNA in axotomized retinal ganglion cells (Fig. 


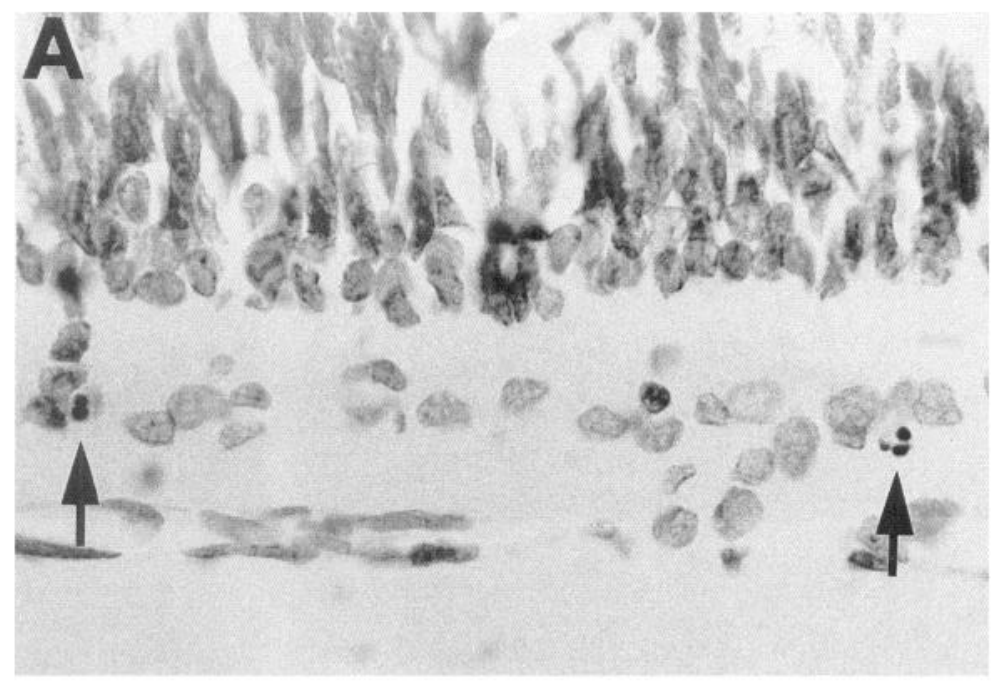

Figure 7. Colocalization of pyknosis and DNA fragmentation. The same eye section ( $\mathrm{P} 0,24 \mathrm{hr}$ after lesion) has been processed for the in situ detection of DNA fragmentation $(B)$, and then later stained with cresyl violet $(A)$, for the detection of pyknotic nuclei. The same two cells are labeled by both methods. Scale bar, $10 \mu \mathrm{m}$.

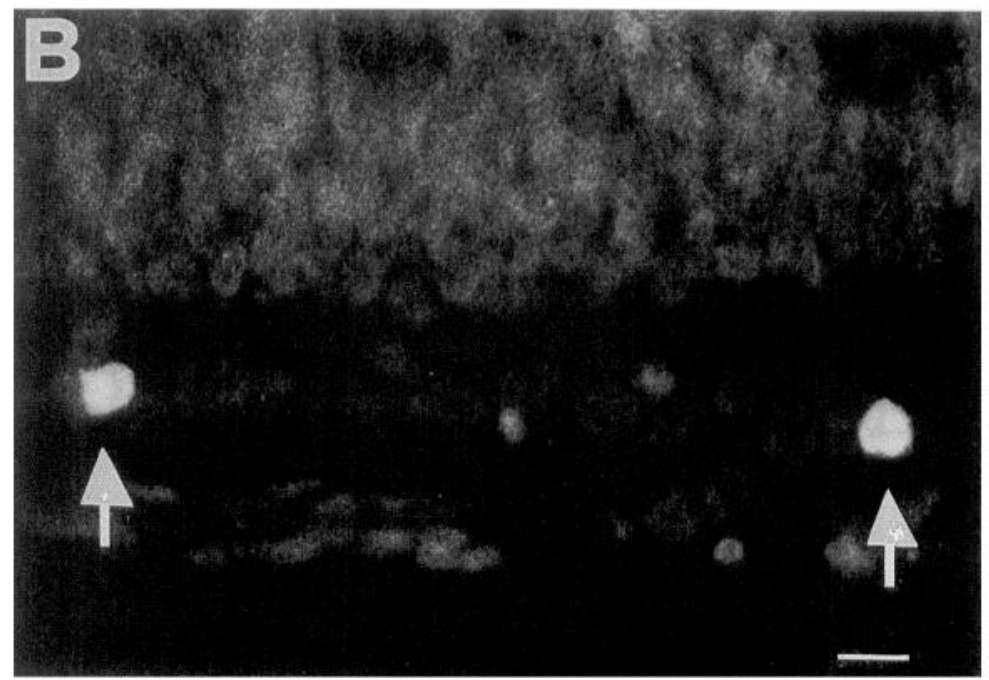

$6 B)$. Intraocular injection of actinomycin $\mathrm{D}(n=5)$ reduces the number of labeled cells from 3.50 to 1.29 (over $100 \mu \mathrm{m}$ ), while after cycloheximide $(n=5)$, the number of labeled cells is decreased to 0.87 (Fig. $8 B$ ). Figure $8 A$ shows that the administration of actinomycin $\mathrm{D}$ and cycloheximide after the lesion is able to reduce the number of cells displaying fragmented DNA to, respectively, $37 \%$ and $25 \%$ when compared to control lesioned retinas $(n=6)$. Similarly, the quantitative analysis of unlabeled cells (Fig. $8 B$ ), shows that protein synthesis inhibitors prevent the reduction in unlabeled cells; the number of unlabeled cells in actinomycin D and cycloheximide-treated eyes is comparable to that found in normal unlesioned retinas $(p>0.05)$.

\section{Discussion}

Our findings show that axotomy of retinal ganglion cells in the neonatal rat induces a process of apoptosis. Indeed, all criteria normally adopted to identify this process are met: inhibition of gene transcription and translation prevents the typical morphological (pyknosis) and biochemical (DNA fragmentation) hallmarks of apoptosis, and survival of ganglion cells is increased by this treatment. The criteria that we have selected in order to identify apoptotic cell death are among the most typical features of apoptosis (Bursch et al., 1992; Johnson and Deckwerth, 1993).
The temporal sequence of the events leading to cell death has not been elucidated; it has been proposed that the synthesis of an endonuclease could result in the fragmentation of DNA, and that this could determine the condensation of the nucleus. However, not all these features are necessarily found in all cases of apoptosis.

Apoptosis is described as a physiological type of cell death occurring throughout phylogenesis during normal development of several structures, including the nervous system (Kerr et al., 1972; Wyllie et al., 1980; Oppenheim, 1991). In particular, in the mammalian nervous system, a striking excess of neurons is initially formed, to be later eliminated; depending on the structure, up to $50-70 \%$ of these cells disappear during normal development. This naturally occurring death is generally correlated with the period of synaptogenesis, and is, for this reason, believed to play a role in the numerical matching between preand postsynaptic partners, and to contribute to the establishment of specificity in the nervous system. This massive neuronal death has been hypothesized to be the result of competition for target-derived trophic factors (Cowan et al., 1984). While in $C$. elegans neuronal death during development is known to be a cell-autonomous programmed cell death (Ellis et al., 1991; Oppenheim, 1991), in vertebrates existing evidence supports the 

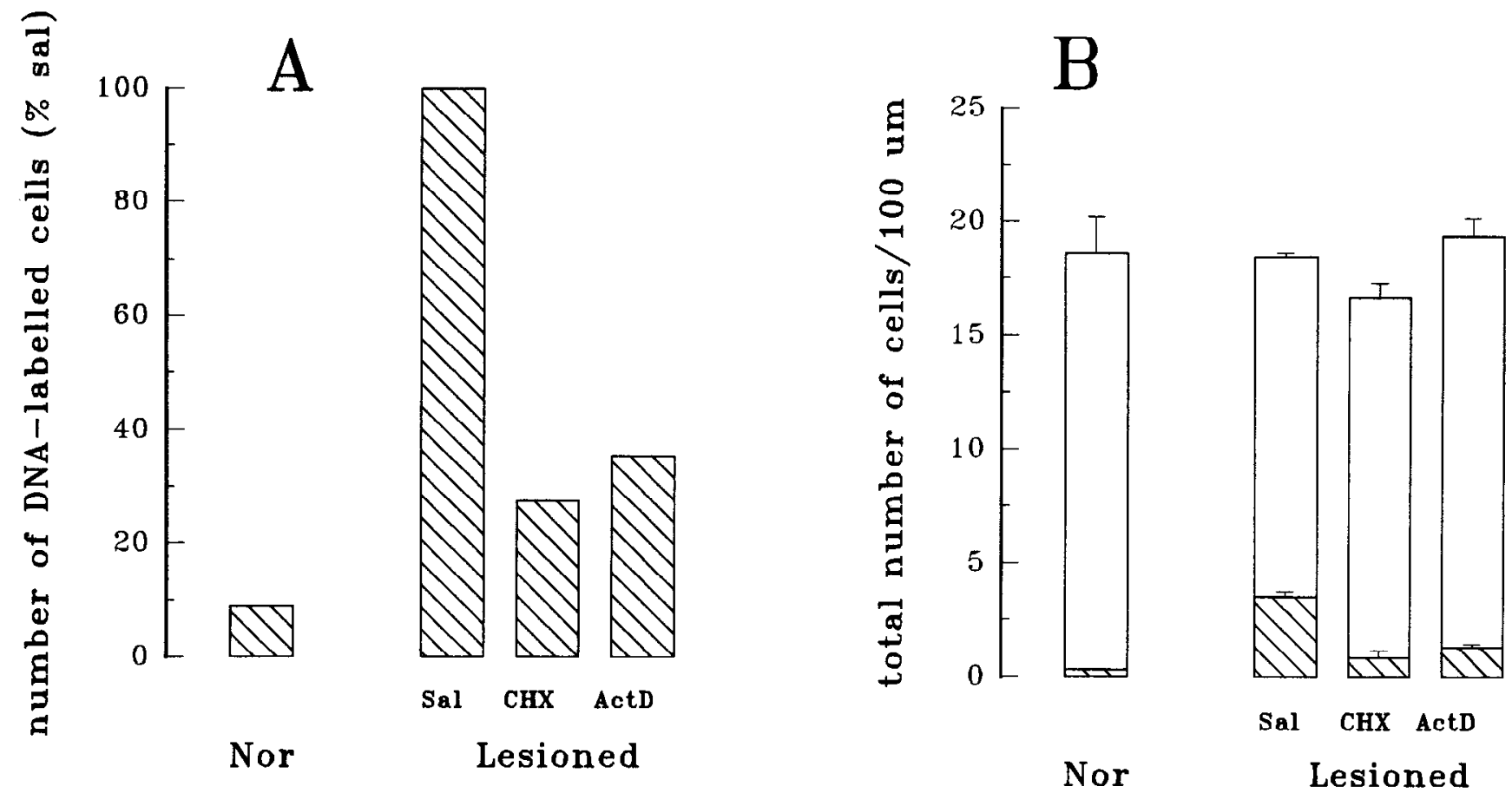

Figure 8. Effects of protein synthesis inhibition on DNA fragmentation. $A$, Number of cells displaying fragmented DNA expressed as a percentage of lesioned control retinas (saline). Both inhibitors significantly reduce the number of labeled cells at $24 \mathrm{hr}$ postlesion, when compared to salineinjected lesioned retinas $(\mathrm{Sal})$. With actinomycin D DNA-fragmented cells decrease to $37 \%$, while cycloheximide reduces this value to $25 \%$. $B$, Total number of cells, including labeled and unlabeled cells, in normal unlesioned retinas and after lesion. Open bars represent the total number of cells (labeled plus unlabeled cells) counted in the retinal ganglion cell layer, while solid bars represent the number of labeled cells. The number of unlabeled cells after treatment with both protein synthesis inhibitors is higher than in saline-treated lesioned eyes, and is, in the case of actinomycin $\mathrm{D}$, comparable to that found in normal unlesioned retinas $(p=0.87)$. The total number of cells counted in lesioned and unlesioned retinas is comparable in all four bars $(p>0.05)$. Error bars indicate SE.

view that naturally occurring cell death is regulated by cellular interactions. This is shown, for example, by the observation that chick embryonic neurons of the PNS depend on the size of the target they innervate for their survival (Hamburger and LeviMontalcini, 1949; Hamburger, 1975). Several reports exist in the literature describing neuronal death induced by trophic factor deprivation in culture as an active process, depending on protein synthesis (Martin et al., 1988; Scott and Davies, 1990; Rukenstein et al., 1991; Allsopp et al., 1993). Unfortunately, in vivo evidence for a similar phenomenon is much more limited. Oppenheim and co-workers showed that in the chick embryonic sensory and motor neurons both naturally occurring cell death and axotomy-induced degeneration constitute a metabolically active process (Oppenheim et al., 1990). Our results, for the first time in the mammalian nervous system, and precisely in retinal ganglion cells, lead to the same conclusions, namely, that spontaneous as well as injury-induced neuronal death are dependent on protein transcription and translation. A possible interesting conclusion from this set of results in the developing chick and rat is that the same (or a similar) program of cell death utilized during normal development can be reutilized in certain pathological conditions. The similarity between these two physiological and pathological types of neuronal death could be explained by a sudden lack of neurotrophic factor, occurring in the first case for missing connection with the target, and in the second for a disconnection caused by the injury.

Necrosis is unlikely to play an important role in our system, although it cannot be excluded. This is supported by two main observations: (1) the reduction in surviving cells $24 \mathrm{hr}$ postlesion coincides with the increase in pyknosis; (2) inhibition of protein synthesis rescues the vast majority of ganglion cells, indicating that apoptosis can account for the degeneration that takes place within the first $24 \mathrm{hr}$ postlesion. We cannot, however, rule out the intervention of necrotic degeneration at some later stages.

We have noticed that the time selected for the administration of protein synthesis inhibitors is critical for their efficacy. Actinomycin D (transcription inhibitor) and cycloheximide (translation inhibitor) showed to be effective only if administered, respectively, 12 and $20 \mathrm{hr}$ postlesion, suggesting that after this time a program of cell death has already been triggered. This observation leads us to hypothesize that the transcription of some "toxic" gene starts $12 \mathrm{hr}$ postlesion, while the synthesis of the corresponding protein takes place at $20 \mathrm{hr}$. It is interesting to note that although the efficacy of actinomycin $D$ in inhibiting protein translation at $24 \mathrm{hr}$ postlesion is not very high $(50 \%$ of ${ }^{35} \mathrm{~S}$-methionine is incorporated) (Fig. $2 B$ ), the level of pyknosis is extremely reduced (Fig. $2 A$ ), and most cells are rescued (see surviving cells, Fig. 4). The partial block of protein synthesis is presumably due to the presence of mRNAs already transcribed before $12 \mathrm{hr}$.

The molecular mechanisms involved in the apoptotic cell death are currently under study in many laboratories; so far, the only gene identified with inhibitory effects on apoptotic death is the oncogene bcl-2. In vitro evidence that this gene could be involved in ncuronal apoptosis comes from overexpression of this gene in neurons deprived of trophic factors (Garcia et al., 1992; Allsopp et al., 1993; Mah et al., 1993).

Concerning the first triggering signals inducing this type of 
cell death, various hypotheses have been proposed in the literature. Substantial evidence points to the lack of neurotrophic factors as responsible for the induction of apoptotic death. Johnson and co-workers have shown that the absence of NGF induces apoptotic death of sympathetic neurons in culture (Martin et al., 1988). From these experiments they have inferred the presence of a target-derived neurotrophic factor that would normally suppress an intrinsic suicide program, by inhibiting the expression of "cell-death genes" (see also Johnson and Deckwerth, 1993). It has also been proposed that neurotrophic factors could act posttranslationally by inhibiting the activity of these genes (Edwards et al., 1991; Rukenstein et al., 1991). In accordance with this suicide program hypothesis, our in vivo experiments show that axotomy-induced degeneration is dependent on protein synthesis. Also consistent with this is the observation that NGF, as well as other neurotrophic factors, is critical for the survival of axotomized adult retinal ganglion cells both in vitro (Johnson et al., 1986; Thanos et al., 1989) and in vivo (Carmignoto et al., 1989; Mansour-Rabay et al., 1992; Mey and Thanos, 1993) as wcll as in nconatal rats (Rabacchi ct al., 1992).

Other authors point to calcium as playing a critical role in triggering the process of apoptosis (Nicotera et al., 1992). A massive entry of calcium could trigger this process (see Ellis et al., 1991), either by activating a hypothetical calcium-dependent endonuclease, or by inducing its upregulation. A recent hypothesis formulated by Cheng and Mattson proposes that the mechanisms by which trophic factors, such as NGF and bFGF, exert their protective effect on injured neurons could be through a stabilization in calcium homeostasis (Cheng and Mattson, 1991). The notion that disparate types of neuronal injuries are associated with calcium deregulation (Mattson, 1990; Strautman et al., 1990; Choi, 1992; Heizmann and Braun, 1992; Landfield et al., 1992) and the observation that their effects can be partially prevented by trophic factors (Fisher et al., 1987, 1991; Cheng and Mattson, 1991) suggest that these different pathologies could share similar mechanisms of degeneration. Our findings of apoptosis in axotomized retinal ganglion cells raise the question as to whether a similar type of active, apoptotic death could occur in other neurodegenerative conditions.

Our present data are limited to the experimental conditions of a lesion to the CNS at early postnatal ages; the young age has been chosen for technical reasons, namely, because of the short delay between axotomy and degeneration. In the adult rat, the degeneration of retinal ganglion cells requires longer times, which is interpreted to be due to a minor dependence on retrograde trophic factor. To analyze whether protein synthesis is necessary for this degeneration process would be very difficult in the adult, since long treatments with protein synthesis inhibitors are toxic. Although we have observed the appearance of pyknotic ganglion cells during retrograde degeneration after axotomy in the adult (unpublished observations), we do not know whether these pyknotic cells are the expression of active cell death; if this were the case, and if similar mechanisms were present also in other parts of the nervous system, our findings could have a bearing in directing neurobiological and clinical research in the field of degeneration/regeneration.

\section{References}

Allsopp TE, Wyatt S, Paterson HF, Davies AM (1993) The protooncogene bcl-2 can selectively rescue neurotrophic factor-dependent neurons from apoptosis. Cell 73:295-307.

Beazley LD, Perry VH, Baker B, Darby EJ (1987) An investigation into the role of ganglion cells in the regulation of division and death of other retinal cells. Dev Brain Res 33:169-184.

Bursch W, Oberhammer F, Schulte-Hermann R (1992) Cell death by apoptosis and its protective role against disease. Trends Pharmacol Sci 13:245-251.

Carmignoto G, Maffei L, Candeo P, Canella R, Comelli C (1989) Effects of NGF on the survival of rat retinal ganglion cells following optic nerve section. J Neurosci 9:1263-1272.

Cheng B, Mattson MP (1991) NGF and bFGF protect rat hippocampal and human cortical neurons against hypoglycemic damage by stabilizing calcium homeostasis. Neuron 7:1031-1041.

Choi DW (1992) Excitotoxic cell death. J Neurobiol 23:1261-1276.

Cohen JJ, Duke C (1992) Apoptosis and programmed cell death in immunity. Annu Rev Immunol 10:267-293.

Cowan WM, Fawcett JW, O'Leary DDM, Stanfield BB (1984) Regressive events in neurogenesis. Science 225:1258-1265.

Di Stefano PS, Schweitzer JB, Taniuchi M, Johnson EM (1985) Selective destruction of nerve growth factor-bearing cells in vitro using a hybrid toxin composed of ricin A chain and a monoclonal antibody against the nerve growth factor receptor. J Cell Biol 101:1107-1114.

Duvall E, Wyllie AH (1986) Death and the cell. Immunol Today 7:115-119.

Edwards SN, Buckmaster AE, Tolkovsky AM (1991) The death programme in cultured sympathetic neurones can be suppressed at the posttranslational level by nerve growth factor, cyclic AMP, and depolarization. J Neurochem 57:2140-2143.

Ellis RE, Yuan J, Horvitz R (1991) Mechanisms and functions of cell death. Annu Rev Cell Biol 7:663-698.

Fisher W, Gage FH, Bjorklund A, Williams LR, Varon S, Gage FH (1987) Amelioration of cholinergic neuron atrophy and spatial memory impairment in aged rats by nerve growth factor. Nature 329:6568.

Fisher W, Bjorklund A, Chen K, Gage FH (1991) NGF improves spatial memory in aged rodents as a function of age. J Neurosci 11: 1889-1906.

Garcia I, Martinou I, Tsujimoto Y, Martinou JC (1992) Prevention of programmed cell death of sympathetic neurons by the bcl-2 protooncogene. Nature 258:302-304.

Gavricli Y, Sherman Y, Ben-Sasson SA (1992) Identification of programmed cell death in situ via specific labeling of nuclear DNA fragmentation. J Cell Biol 119:493-501.

Hamburger V (1975) Cell death in the development of the lateral motor column of the chick embryo. J Comp Neurol 160:535-546.

Hamburger V, Levi-Montalcini R (1949) Proliferation, differentiation and degeneration in the spinal ganglias of the chick embryo under normal and experimental conditions. J Exp Zool 111:457-502.

Harvey AR, Robertson D (1992) Time-course and extent of retinal ganglion cell death following ablation of the superior colliculus in neonatal rats. J Comp Neurol 325:83-94.

Heizmann CW, Braun K (1992) Changes in $\mathrm{Ca}^{2+}$-binding proteins in human neurodegenerative disorders. Trends Neurosci 15:259-264.

Horsburgh GM, Sefton AJ (1987) Cellular degeneration and synaptogenesis in the developing retina of the rat. J Comp Neurol 263:553566.

Johnson EM, Deckwerth TL (1993) Molecular mechanisms of developmental neuronal death. Annu Rev Neurosci 16:31-46.

Johnson JE, Barde Y-A, Schwab M, Thoenen H (1986) Brain-derived neurotrophic factor supports the survival of cultured rat retinal ganglion cells. J Neurosci 6:3031-3038.

Kerr JFR, Wyllie AH, Currie AR (1972) Apoptosis: a basic biological phenomenon with wide-ranging implications in tissue kinetics. $\mathrm{Br} \mathrm{J}$ Cancer 26:239-257.

Lam K, Sefton AJ, Bennett MR (1982) Loss of axons from the optic nerve of the rat during early postnatal development. Dev Brain Res $3: 487-491$.

I andfield PW, Thibault O, Mazzanti ML, Porter NM, Kerr DS (1992) Mechanisms of neuronal death in brain aging and Alzheimer's disease: role of endocrine-mediated calcium dyshomeostasis. J Neurobiol 23: $1247-1260$.

Mah SP, Zhong LT, Liu Y, Roghany A, Edwards RH, Bredesen DE (1993) The protooncogene bcl-2 inhibits apoptosis in PC12 cells. J Neurochem 60:1183-1186.

Mansour-Rabaey S, Bray GM, Aguayo AJ (1992) In vivo effects of brain-derived neurotrophic factor (BDNF) and injury on the survival of axotomized retinal ganglion cells in adult rats. Mol Biol Cell 3:333a. Martin DP, Schmidt RE, Di Stefano P, Lowry OH, Carter JG, Johnson 
EM (1988) Inhibitors of protein synthesis and RNA synthesis prevent neuronal death caused by nerve growth factor deprivation. J Cell Biol 106:829-843.

Mattson MP (1990) Antigenic changes similar to those seen in neurofibrillary tangles are induced by glutamate and $\mathrm{Ca}^{2+}$ influx in cultured hippocampal neurons. Neuron 4:105-117.

Mey J, Thanos S (1993) Intravitreal injections of neurotrophic factors support the survival of axotomized retinal ganglion cells in adult rats in vivo. Brain Res 602:304-317.

Miller NM, Oberdorfer M (1981) Neuronal and neuroglial responses following retinal lesions in the neonatal rats. J Comp Neurol 202: 493-504.

Misantone LJ, Gershenbaum M, Murray M (1984) Viability of retinal ganglion cells after optic nerve crush in adult rats. J Neurocytol 13: 449-465.

Nicotera P, Bellomo G, Orrenius S (1992) Calcium-mediated mechanisms in chemically induced cell death. Annu Rev Pharmacol Toxicol 32:449-470.

Oppenheim RW (1991) Cell death during development of the nervous system. Annu Rev Neurosci 14:453-501.

Oppenheim RW, Prevette D, Tytell M, Homma S (1990) Naturally occurring and induced neuronal death in the chick embryo in vivo requires protein and RNA synthesis: evidence for the role of cell death gencs. Dev Biol 138:104-113.

Perry VH, Linden R (1982) Evidence for dendritic competition in the developing retina. Nature 297:683-685.

Perry VH, Henderson Z, Linden R (1983) Postnatal changes in retinal ganglion cell and optic axon populations in the pigmented rat. J Comp Neurol 219:356-368.

Potts RA, Dreher B, Bennett MR (1982) The loss of ganglion cells in the developing retina of the rat. Dev Brain Res 3:481-486.

Rabacchi SA, Ensini M, Gravina A, Fagiolini M, Bonfanti L, Maffei L (1992) Retinal ganglion cell degeneration after optic nerve lesion and nerve growth factor protective effect in the developing rat. Soc Neurosci Abstr 18:28.3.

Raff MC (1992) Social controls on cell survival and cell death. Nature $356: 397-400$.

Rukenstein A, Rydel RE, Greene LA (1991) Multiple agents rescue PC12 cells from serum-free cell death by translation- and transcription-independent mechanisms. J Neurosci 11:2552-2563.

Scott SA, Davies AM (1990) Inhibition of protein synthesis prevents cell death in sensory and parasympathetic neurons deprived of neurotrophic factor in vivo. J Neurobiol 21:630-638.

Strautman AF, Cork RJ, Robinson KR (1990) The distribution of free calcium in transected spinal axons and its modulation by applied electrical fields. J Neurosci 10:3564-3575.

Thanos S, Bahr M, Barde Y-A, Vanselow J (1989) Survival and axonal elongation of adult rat retinal ganglion cells. Eur J Neurosci 1:19-26. Villegaz-Perez M-P, Vidal-Sanz M, Rasminsky M, Bray GM, Aguayo AJ (1992) Rapid and protracted phases of retinal ganglion cell loss follow axotomy in the optic nerve of adult rats. J Neurobiol 24:2336.

Wyllie AH, Kerr JFR, Currie AR (1980) Cell death: the significance of apoptosis. Int Rev Cytol 68:251-300. 